\title{
Soveltuuko kierrätyslannoite ammoniumsulfaatti tankkiseoksiin herbisidien kanssa?
}

\author{
Pentti Ruuttunen ${ }^{1)}$, Petri Kapuinen ${ }^{2)}$ \\ ${ }^{1)}$ Luke Kasvinterveys, 31600 Jokioinen \\ ${ }^{2)}$ Luke Biojalostusteknologiat ja tuotteet, 20520 Turku
}

Luonnonvarakeskuksessa Jokioisissa tutkittiin vuonna 2017 kolmessa kenttäkokeessa nestemäisen ammoniumsulfaatin soveltuvuutta tankkiseoksiin viljoilla yleisesti käytettävien rikkakasvien torjuntaaineiden (herbisidien) kanssa. Nestemäisenä lannoitteena ammoniumsulfaatin voi levittää kasvinsuojeluruiskulla, ja rikkakasvien torjuntaan yhdistettynä lannoitus ei lisäisi ajokertoja. Lisäksi ammoniumsulfaatin on eräissä tutkimuksissa havaittu parantavan glyfosaatin tehoa. Kenttäkokeet liittyvät Nesteravinne-hankkeeseen (2017 - 2019), jossa tutkitaan erityisesti kierrätystypen käyttöä maataloudessa nestemäisinä lannoitevalmisteina. Keväällä 2017 tehtiin esitestit nestemäisen ammoniumsulfaatin (350 $\mathrm{g} \mathrm{kg}^{-1}$ ) teknisestä soveltuvuudesta tankkiseoksiin glyfosaattivalmiste Roundup Bion ja yhdeksän muun viljanviljelyssä yleisesti käytetyn herbisidivalmisteen sekä kahden kiinniteaineen kanssa. Roundup Bio, K-Trio-neste ja Ariane $\mathrm{S}$ soveltuivat sellaisenaan ammoniumsulfaattiliuoksen kanssa sekoitettaviksi ja kasvinsuojeluruiskulla levitettäviksi. Pienannosvalmisteet Tooler, Logran 20 WG, Express 50 SX ja Biathlon 4D soveltuivat myös, mutta ennen ammoniumsulfaattiliuokseen sekoittamista ne oli liuotettava pieneen määrään vettä. K-MCPAneste, Primus ja Starane XL eivät liuenneet ammoniumsulfaattiliuokseen, kuten eivät myöskään kiinnitteet Sito Plus ja Dash. Roundup Bio hyväksyttiin valmisteeksi glyfosaattikokeeseen. Kauralla ja ohralla tehtäville kenttäkokeille valittiin neljä herbisidivalmistetta: K-Trio-neste (diklorproppi-P + MCPA + mekoproppi-P), Ariane S (MCPA + fluroksipyyri + klopyralidi), Tooler (tritosulfuroni) ja Logran 20 WG (triasulfuroni). Glyfosaattikoe perustettiin juolavehnäiselle pellolle, ja kokeessa testattiin normaalia pienempien Roundup Bio -annosten tehoa tankkiseoksissa ammoniumsulfaatin kanssa ennen kevätvehnän suorakylvöä. Ammoniumsulfaatin ja Roundup Bion normaalin käyttömäärän 3,0 l ha"-1 tankkiseos ilman kiinnitettä tehosi juolavehnään, voikukkaan ja pelto-orvokkiin yhtä hyvin kuin sama Roundup Bio -annos vesiliuoksessa Sito Plus -kiinnitteen kanssa. Pienin Roundup Bion käyttömäärä 1,01 ha $^{-1}$ ammoniumsulfaatin kanssa ilman kiinnitettä tehosi rikkakasveihin lähes yhtä hyvin kuin normaaliannos 3,0 $\mathrm{l} \mathrm{ha-1}$. Herbisidikokeissa kauralla ja ohralla esiintyi runsaasti kevätviljoille tyypillisiä siemenrikkakasveja. Ammoniumsulfaatti aiheutti polttovioitusta kauran ja ohran lehdissä tankkiseoksissa K-Trio-nesteen ja Ariane S:n kanssa. Mm. jauhosavikkaan ja peltoemäkkiin sulfonyyliureavalmisteiden Tooler ja Logran 20 WG teho oli parempi vesiliuoksessa Sito Plus -kiinnitteen kanssa kuin ammoniumsulfaattiliuoksessa ilman kiinnitettä. Kenttäkokeiden satotulokset ja glyfosaattikokeen maanäytteistä tehtävien glyfosaattianalyysien tulokset puuttuvat tätä abstraktia kirjoitettaessa. Glyfosaattikokeen käsittelyjen jälkivaikutus juolavehnään havainnoidaan kesällä 2018.

Asiasanat: Ammoniumsulfaatti, herbisidit, tankkiseos, vilja

\section{Johdanto}

Glyfosaatti on eniten käytetty kasvinsuojeluaine maataloudessa. Vuonna 2014 sen myyntimäärä Suomessa oli 710 tonnia, joka vastaa 44 \% kaikkien kasvinsuojeluaineiden myyntimääristä. Glyfosaatti on aiheuttanut viime aikoina paljon keskustelua sen syöpävaaraepäilyjen vuoksi. EU- hyväksynnän umpeutuessa syksyllä 2017 glyfosaatin uudelleenhyväksyntä oli vakavasti vaakalaudalla. Lopulta EU:n muutoksenhakukomitea päätti 27.11.2017 jatkaa glyfosaatin hyväksyntää viideksi vuodeksi eli vuoden 
2022 loppupuolelle saakka. Glyfosaatin apuaineista polyetoksyloitu talialkyyliamiini (POEA) todettiin kuitenkin terveydelle haitalliseksi, ja sitä sisältävien valmisteiden käyttö kiellettiin EU:n päätöksellä jo 1.8.2016.

Ammoniumsulfaatin käyttöä glyfosaatin vaikutuksen tehostamiseen tutkittiin 70 ja 80-luvuilla intensiivisesti, koska glyfosaatin hinta oli silloin huomattavasti nykyistä korkeampi (Suwunnamek ja Parker 1975, Turner ja Loader 1980, O’Sullivani 1981, Hallgren ja Nilsson 1989a, 1989b). Käyttömäärän pienentämisestä sen tehoa parantavilla aineilla oli merkittävää taloudellista hyötyä viljelijälle. Suomessa glyfosaatin käyttö keskittyy viljapelloille, joilla siitä käytetään $70 \%$ (Peltonen 2016). Nurmilla käytetään $12 \%$ ja öljy- ja palkokasveilla $8 \%$. Muu käyttö on vähäistä. Pääkäyttö on syksyllä, 26 \% (yleensä juolavehnän torjuntaan viljojen puinnin jälkeen). Suorakylvöön viittaava käyttö huhti - toukokuussa on $20 \%$. Nykyisin ainekustannus esimerkiksi ennen suorakylvöä tehtävässä juolavehnän torjunnassa suositelluilla varsin suurilla annoksilla on vain noin $15-20 €$ ha $^{-1}$, jolloin annoksen vähentämisestä saatava taloudellinen hyöty säästyneenä ainekustannuksena jää pieneksi. Kasvustossa tehtävässä torjunnassa muilla aineilla ainekustannus on $30-75 €$. Sen sijaan annoksen pienentämisellä voitaisiin vähentää haitallisten hajoamistuotteista aiheutuvaa kuormitusta vastaavasti. Hajoamistuotteista keskeisin on AMPA (Siimes 2016). Sen hajoamisnopeus on pienempi kuin glyfosaatin, joten sen pitoisuus maassa voi olla suurempi kuin glyfosaatin. Hajoamistuotteita voi olla maassa, siinä kasvaneissa kasveissa ja vedessä. Glyfosaatti ja sen hajoamistuotteet tarttuvat tehokkaasti maahan mutta ovat hyvin vesiliukoisia. Ne leviävät ympäristöön tehokkaimmin juuri veden mukana, mutta Suomessa havaitut suurimmatkin pitoisuudet pohjavesissä ovat olleet hyvin pienet suhteessa ehdotettuihin ympäristön laatunormeihin.

Suorakylvössä juolavehnän torjuminen on kohtuullisen vaikeaa ilman kemiallista torjuntaa. Palaamisesta perinteiseen kylvötapaan lisäisi merkittävästi työnmenekkiä lisääntyneiden muokkaustoimien takia. Näin ollen siitä, että glyfosaatin käyttöä voitaisiin jatkaa vähentämällä hajoamistuotteiden kuormitusta, olisi merkittävää taloudellista hyötyä myös maataloudelle.

Ammoniumsulfaattia voitaisiin luontevasti käyttää myöhemminkin kasvukauden aikana eri kasvinsuojelutoimenpiteiden yhteydessä lisälannoitukseen. Kun lisälannoitus voidaan yhdistää johonkin kasvinsuojelutoimenpiteeseen, siitä ei aiheudu ylimääräistä työkustannusta. Osa typpilannoituksesta voidaan jättää keväällä antamatta ja sen taso voidaan säätää kohdalleen kasvin tarpeen mukaan kasvukauden mukaisesti. Tässä tutkimushankkeessa päätettiin tutkia ensin, soveltuisiko ammoniumsulfaatti tankkiseoksiin viljoilla yleisesti käytettyjen rikkakasvien torjuntaaineiden eli herbisidien kanssa. Esimerkiksi Yhdysvalloissa on käytetty ammoniumsulfaattia kiinnitteen korvikkeena erityisesti herbisidien kanssa, jotka ovat ns. heikkoja happoja (Pratt ym. 2003, Wosnica ym. 2003). Yleensä tarkoituksena on ollut kuitenkin herbisidin tehon parantaminen, ja ammoniumsulfaatin pitoisuus tankkiseoksissa on ollut melko pieni. Tässä hankkeessa on kuitenkin tarkoitus selvittää voitaisiinko lisälannoitteena käytettävää mahdollisimman väkevää ammoniumsulfaattiliuosta levittää herbisidien kanssa tankkiseoksena siten, että herbisidien teho säilyy normaalina eikä viljelykasveille aiheudu vioituksia.

\section{Materiaalit ja menetelmät}

Tankkiseos-esitestit

Keväällä 2017 tehtiin esitestit nestemäisen ammoniumsulfaatin teknisestä soveltuvuudesta tankkiseoksiin glyfosaattivalmiste Roundup Bion ja yhdeksän muun viljanviljelyssä yleisesti käytetyn herbisidivalmisteen sekä kahden kiinniteaineen kanssa. 
1. Esitestiin valittiin yleinen glyfosaattivalmiste Roundup Bio ja yhdeksän muuta yleisintä (herbisidivalmisteiden myyntitilaston 2015 mukaan) herbisidivalmistetta Tooler, K-MPCAneste, K-Trio-neste, Logran 20 WG, Express 50 SX, Ariane S, Oxitril, Primus ja Starane XL

2. Valmistettiin kiteisestä ammoniumsulfaatista 35 paino-\% vesiliuos

3. Kunkin herbisidivalmisteen ja ammoniumsulfaatin (AMS) tankkiseosten toimivuus testattiin seuraavasti

4. Herbisidivalmiste sekoitettiin ämpärissä 1 litraan $35 \%$ AMS -liuosta ( $20^{\circ} \mathrm{C}$ neste)

5. Sekoitussuhde: Herbisidin normaali käyttömäärä + AMS -liuoksen käyttömäärä 2001 ha $^{-1}$

6. Tutkittiin silmämääräisesti liukeneeko sekoitusämpärissä

7. Lisättiin mahdollinen kiinnite ja tehtiin uudet havainnot sekoittumisesta

8. Kaadettiin siivilällä varustetun suppilon läpi koeruuturuiskun tankkiin, tutkittiin jääkö siivilään jotain

9. Ruiskutettiin koeruuturuiskun läpi (Hardi 4110-12 -viuhkasuuttimet, 2.0 bar paine, ulkoilma 7 $\left.{ }^{\circ} \mathrm{C}\right)$ ja kerättiin joka suuttimen tuotto ämpäreihin

10. Punnittiin ruiskutteen määrä ämpäreissä

11. Tutkittiin ja pestiin suuttimet ja suutinten suodattimet

12. Testattiin seuraava valmiste samalla tavoin

13. Tehtiin uusintatesti ns. pienannosaineiden liukenevuudesta siten, että valmiste liuotettiin ensin pieneen määrään vettä ja sitten vasta AMS -liuokseen

14. Valittiin kenttäkokeisiin sellaisia valmisteita, jotka liukenivat hyvin AMS -liuokseen (joko suoraan tai sen jälkeen kun ne oli liuotettu pieneen määrään vettä) ja jotka läpäisivät ruiskun siten, että suutinten tuotto oli tasainen eikä suutinten suodattimiin jäänyt epäpuhtautta

\section{Kenttäkokeet}

Toteutettiin kolme kenttäkoetta Jokioisissa kasvukaudella 2017. Kenttäkokeet tehtiin GEPlaatujärjestelmän mukaisesti kasvinsuojeluainekokeiden EPPO PP1 -standardeja (https://pp1.eppo.int/) noudattaen. Kenttäkokeissa oli neljä kerrannetta ja koemalli satunnaistettujen lohkojen muotoinen. Koeruutujen koko oli $3 \mathrm{~m}$ x $8 \mathrm{~m}$, puitavat nettoruudut $2 \mathrm{~m}$ x $6.8 \mathrm{~m}$. Glyfosaattikokeen paikaksi oli valittu erittäin juolavehnäinen peltolohko Jokioisten Minkiössä, joka oli tarkoituksella jätetty ruiskuttamatta glyfosaatilla ja kyntämättä edellissyksynä. Kaksi muuta koetta toteutettiin edellissyksynä kynnetyillä ja ennen kylvöä äkeellä kylvömuokatuilla lohkoilla, joille taimettui runsaasti eri siemenrikkakasvilajeja ennen ruistutusta.

Koe numero H-17-045-34Glyfosaattikoe suorakylvetyllä Wanamo -kevätvehnällä

- Juolavehnäinen lohko, ruiskutus juuri ennen kylvöä

- Tutkimuskysymykset: 1) Voidaanko Roundup Bio -glyfosaattivalmisteen käyttömäärää pienentää rikkakasvitehon kärsimättä lisäämällä tankkiseokseen AMS:ia? 2) Miten käsittelyt vaikuttavat maan ja vehnäsadon glyfosaattipitoisuuteen?

- Koejäsenet:

1. Käsittelemätön

2. $35 \%$ AMS $200 \mathrm{l} \mathrm{ha}^{-1}$

3. $35 \%$ AMS $57 \mathrm{l} \mathrm{ha}^{-1}$

4. Roundup Bio $3.01 \mathrm{lha}^{-1}+$ Sito Plus $0.51 \mathrm{ha}^{-1}$

5. $35 \%$ AMS $57 \mathrm{l} \mathrm{ha}^{-1}+$ Roundup Bio $3.0 \mathrm{l} \mathrm{ha}^{-1}$

6. $35 \%$ AMS $57 \mathrm{l} \mathrm{ha}^{-1}+$ Roundup Bio $2.0 \mathrm{l} \mathrm{ha}^{-1}$

7. $35 \%$ AMS 571 ha $^{-1}+$ Roundup Bio 1.01 ha $^{-1}$ 
8. $35 \%$ AMS $200 \mathrm{l} \mathrm{ha}^{-1}+$ Roundup Bio $1.0 \mathrm{l} \mathrm{ha}^{-1}$

Kaikissa ruiskutettavissa koejäsenissä (2-8) ruiskutteen määrä oli 2001 ha $^{-1}$. Kun nestemäisen AMSin

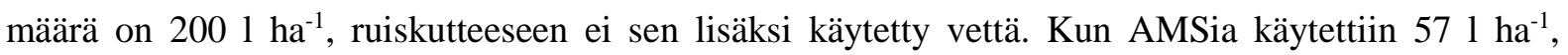
ruiskutteeseen lisättiin vettä 1431 ha $^{-1}$ (nestemäärä yhteensä 2001 ha $^{-1}$ ).

Havainnot:

Visuaaliset tehokkuushavainnot tehtiin juolavehnään, pelto-orvokkiin ja voikukkaan kahdesti kasvukauden aikana

- Viljasato puitiin 23.10.2017 koeruutupuimurilla, lajiteltiin, punnittiin, näytteiden kosteus ja hehtolitrapaino määritettiin => laskettiin kosteusvakioidut ruutusadot

- Säilytettiin ruutusatonäytteet mahdollisia laatuanalyysejä varten

Jäämäanalyysit:

- Glyfosaatin taustajäämät maasta otettiin 5.5.2017 ennen ruiskutusta kerranteittain 0 - 2,5 cm ja 2,5 - 25 cm syvyyksistä. Taustajäämät analysoitiin touko-kesäkuussa 2017

- Heti puinnin jälkeen 25.10.2017 otettiin maanäytteet koejäsenistä 1,4, 5 ja 8 ruuduittain $0-2,5$ cm ja 2,5 - 25 cm syvyyksistä. Näytteet homogenisoitiin ja pakastettiin 31.10.2017, ja glyfosaattijäämät analysoitiin tammikuussa 2018.

- Osanäytteet vehnän jyvistä otettiin lajitelluista näytteistä koejäsenistä 1,4, 5 ja 8 ruuduittain, pakastettiin marraskuussa 2017 ja niistä analysoitiin glyfosaattijäämät tammikuussa 2018

\section{Koe numero H-17-046-34: Herbisidikoe Venla -kauralla ja Koe numero H-17-047-34: Herbisidikoe Vipekka -ohralla}

Molemmilla kokeilla oli samat koesuunnitelmat eli

- Kylvö 13.5.2017 (molemmat kokeet), ruiskutus normaaliin rikkakasvien torjunnan aikaan (19.6.2017 kaura ja 14.6.2017 ohra)

- Neljä yleisesti käytettyä herbisidiä: 2 herbisidiä vaikutustaparyhmästä ALS -estäjät ja 2 herbisidiä vaikutustaparyhmästä synteettiset auksiinit

- ruiskutenesteenä puhdas vesi tai 35 \% AMS -liuos

- Koejäsenet:

1. Käsittelemätön

2. $35 \%$ AMS 2001 ha $^{-1}$

3. K-Trio $1.5 \mathrm{l} \mathrm{ha}^{-1}$ (pienin normaaliannos) (+ $200 \mathrm{l} \mathrm{ha} \mathrm{h}^{-1}$ vettä)

4. $35 \%$ AMS $200 \mathrm{l} \mathrm{ha}^{-1}+$ K-Trio $1.5 \mathrm{l} \mathrm{ha}^{-1}$

5. Ariane S $1.75 \mathrm{l} \mathrm{ha}^{-1}$ (pienin normaaliannos) (+ $200 \mathrm{l} \mathrm{ha}^{-1}$ vettä)

6. $35 \%$ AMS $200 \mathrm{l} \mathrm{ha}^{-1}+$ Ariane S $1.75 \mathrm{l} \mathrm{ha}^{-1}$

7. Tooler $50 \mathrm{~g} \mathrm{ha}^{-1}$ (normaaliannos) (+ $200 \mathrm{l} \mathrm{ha}^{-1}$ vettä) + Sito Plus $0.2 \mathrm{l} \mathrm{ha} \mathrm{a}^{-1}$

8. $35 \%$ AMS $200 \mathrm{l} \mathrm{ha}^{-1}+$ Tooler $50 \mathrm{~g} \mathrm{ha}^{-1}$

9. Logran 20 WG $20 \mathrm{~g} \mathrm{ha}^{-1}$ (normaaliannos) (+ $200 \mathrm{l} \mathrm{ha}^{-1}$ vettä) + Sito Plus 0.21 ha $^{-1}$

10. $35 \%$ AMS $200 \mathrm{l} \mathrm{ha}^{-1}+$ Logran 20 WG $20 \mathrm{~g} \mathrm{ha}^{-1}$ 
Havainnot:

- Visuaaliset tehokkuushavainnot eri rikkakasvilajeihin kahdesti kasvukauden aikana

- Visuaaliset vioitushavainnot viljelykasveissa kahdesti kasvukauden aikana

- Ohra puitiin 7.9.2017 ja kaura 29.9.2017 koeruutupuimurilla, joka punnitsi ruutusadon ja määritti sen kosteuden puinnin yhteydessä => laskettiin kosteusvakioidut ruutusadot

- Otettiin ja säilytettiin ruutusatonäytteet mahdollisia laatuanalyysejä varten

\section{Tulokset}

\section{Esitestit}

Roundup Bio, K-Trio -neste ja Ariane S soveltuivat sellaisenaan AMS -liuoksen kanssa sekoitettaviksi ja kasvinsuojeluruiskulla levitettäviksi. Pienannosvalmisteet Tooler, Logran 20 WG, Express 50 SX ja Biathlon 4D soveltuivat myös, mutta ennen AMS -liuokseen sekoittamista ne oli liuotettava pieneen määrään vettä. K-MCPA -neste muodosti AMS -liuoksessa suolamaista sakkaa ja Primus ja Starane XL muodostivat liuokseen klimppejä. Kiinnitteet Sito Plus ja Dash jäivät rasvapalloiksi AMS -liuoksen pinnalle, jolloin ne eivät toimi ruiskutteessa kiinnitteinä tarkoitetulla tavalla. Kenttäkokeisiin valittiin herbisidivalmisteet Roundup Bio, K-Trio -neste, Ariane S, Tooler ja Logran 20 WG. Kiinnitteet Sito Plus ja Dash jätettiin pois AMS:in ja herbisidien tankkiseoksista.

\section{Kenttäkokeet}

\section{Glyfosaattikoe suorakylvetyllä vehnällä}

5.5.2017 ennen kokeen ruiskutusta otetuista maanäytteistä löytyi analyyseissä aivan vähäisiä taustajäämiä, pääasiassa AMPA:a mutta myös glyfosaattia, sekä 0 - 2,5 cm pintakerroksesta että 2,525 cm kerroksesta. Koetta ruiskutettaessa 16.5.2017 juolavehnä oli jo hyvässä kasvussa 2-3 lehtiasteella, peittäen 21 - 25 \% maan pinnasta. Juuri ennen Wanamo -vehnän kylvöä 26.5.2017 tehdyissä ensimmäisissä tehokkuushavainnoissa glyfosaattikäsittelyjen teho juolavehnään ja harvalukuisina esiintyneisiin voikukkaan ja pelto-orvokkiin näkyvät jo selvästi. Toisissa tehokkuushavainnoissa 14.6.2017 glyfosaatin täysi teho oli tullut esiin ja esitetään taulukossa 1.

Taulukko 1. Glyfosaatti + AMS, suorakylvetty Wanamo -kevätvehnä, Jokioinen. Visuaalisesti havainnoitu teho rikkakasveihin 29 vrk ruiskutuksesta ja vehnäsato 23.10.2017

\begin{tabular}{|c|c|c|c|c|c|c|c|c|c|}
\hline \multirow[t]{2}{*}{$\begin{array}{c}\text { Koej. } \\
\text { nro }\end{array}$} & \multirow[t]{2}{*}{ Koejäsen } & \multicolumn{2}{|c|}{$\begin{array}{c}\text { Juolavehnä } \\
\text { teho \% }\end{array}$} & \multicolumn{2}{|c|}{$\begin{array}{c}\text { Pelto-orvokki } \\
\text { teho } \% \\
\end{array}$} & \multicolumn{2}{|c|}{$\begin{array}{c}\text { Voikukka } \\
\text { teho } \%\end{array}$} & \multicolumn{2}{|c|}{$\begin{array}{c}\text { Kevätvehnä- } \\
\text { sato kg/ha }\end{array}$} \\
\hline & & 14.6.201? & & 14.6.2017 & & 14.6 .201 & & 23.10 & 2017 \\
\hline 1 & Käsittelemätön & 0 & $\mathrm{~b}$ & 0 & C & 0 & $\mathrm{~b}$ & 150 & c \\
\hline 2 & AMS 57 l/ha & 0 & $\mathrm{~b}$ & 0 & c & 0 & $\mathrm{~b}$ & 205 & c \\
\hline 3 & AMS 200 l/ha & 0 & $\mathrm{~b}$ & 0 & C & 0 & $\mathrm{~b}$ & 205 & c \\
\hline 4 & Roundup Bio 3 l/ha + Sito Plus 0.5 l/ha & 98 & $\mathrm{a}$ & 99 & a & 98 & $\mathrm{a}$ & 2196 & $\mathrm{a}$ \\
\hline 5 & Roundup Bio 1 l/ha + AMS 57 l/ha & 90 & a & 90 & $\mathrm{~b}$ & 95 & $\mathrm{a}$ & 1890 & $\mathrm{ab}$ \\
\hline 6 & Roundup Bio 1 l/ha + AMS 200 l/ha & 89 & a & 90 & $\mathrm{~b}$ & 94 & $\mathrm{a}$ & 1453 & $\mathrm{~b}$ \\
\hline 7 & Roundup Bio 2 l/ha + AMS 200 l/ha & 96 & a & 99 & $\mathrm{a}$ & 97 & $\mathrm{a}$ & 2077 & $\mathrm{a}$ \\
\hline 8 & Roundup Bio 3 l/ha + AMS 200 l/ha & 98 & a & 99 & $\mathrm{a}$ & 98 & a & 1968 & $\mathrm{a}$ \\
\hline
\end{tabular}

Ruiskutteen kokonaismäärä aina 200 l/ha

Samalla kirjaimella merkityt keskiarvot eivät eroa tilastollisesti ( $\mathrm{P}=0.05$, Tukey HSD)

Roundup Bion normaali käyttömäärä 3 l/ha torjui kaikki rikkakasvit lähes täydellisesti (98 - 99\% teho) riippumatta siitä, ruiskutettiinko se normaalisti vesiliuoksessa tai ammoniumsulfaattiliuoksessa. $1 \mathrm{l} / \mathrm{ha}$ Roundup Bio -annoksella ammoniumsulfaatin kanssa saatiin myös melko hyvä teho kaikkiin 
rikkakasveihin (89 - 95\%). Tiheä juolavehnä tukahdutti vehnän täysin koejäsenissä ilman glyfosaattia. Vehnäsato jäi heikoksi glyfosaattiruuduissakin (Taulukko 1), mikä johtunee harvahkosta vehnästä ja mahdollisesti juolavehnän juurakoiden allelopaattisista ja mekaanisista vaikutuksista. Maan tai vehnäsadon glyfosaatti- ja AMPA -jäämätulokset eivät ole vielä valmistuneet tätä kirjoitettaessa.

\section{Herbisidikokeet kauralla ja ohralla}

Herbisidikokeissa kauralla ja ohralla esiintyi runsaasti kevätviljoille tyypillisiä siemenrikkakasveja. Ammoniumsulfaatti aiheutti polttovioitusta kauran ja ohran lehdissä tankkiseoksissa K-Trio-nesteen ja Ariane S:n kanssa. Tehokkuushavainnot noin $1 \mathrm{kk}$ ruiskutuksesta kuvaavat käsittelyjen tehoa luotettavimmin (kuvat 1 ja 2). Mm. jauhosavikkaan ja peltoemäkkiin sulfonyyliurea valmisteiden Tooler ja Logran 20 WG teho oli parempi vesiliuoksessa Sito Plus -kiinnitteen kanssa kuin ammoniumsulfaattiliuoksessa ilman kiinnitettä. Myös Ariane S vaikutti tehoavan hiukan paremmin rikkakasveihin vesiliuoksessa kuin AMS -liuoksessa. K-Trio -neste tehosi rikkakasveihin yhtä hyvin AMS -liuoksessa kuin vesiliuoksessa.

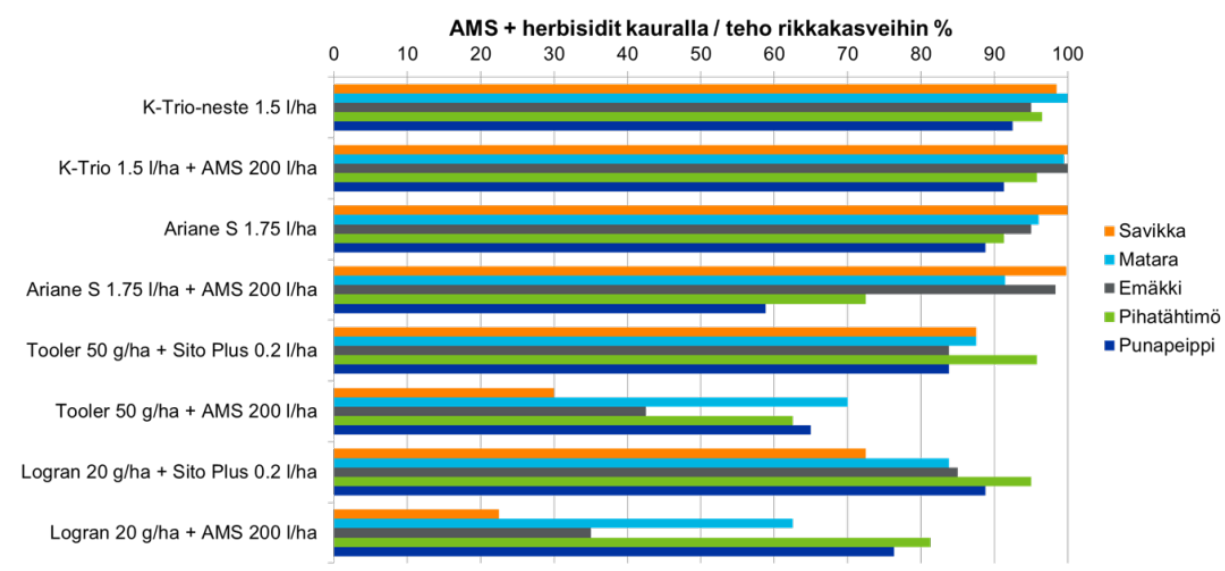

Kuva 1. AMS + herbisidit kauralla, Jokioinen. Käsittelyjen visuaalisesti havainnoitu teho rikkakasveihin 18.7.2017 (29 vrk ruiskutuksesta)

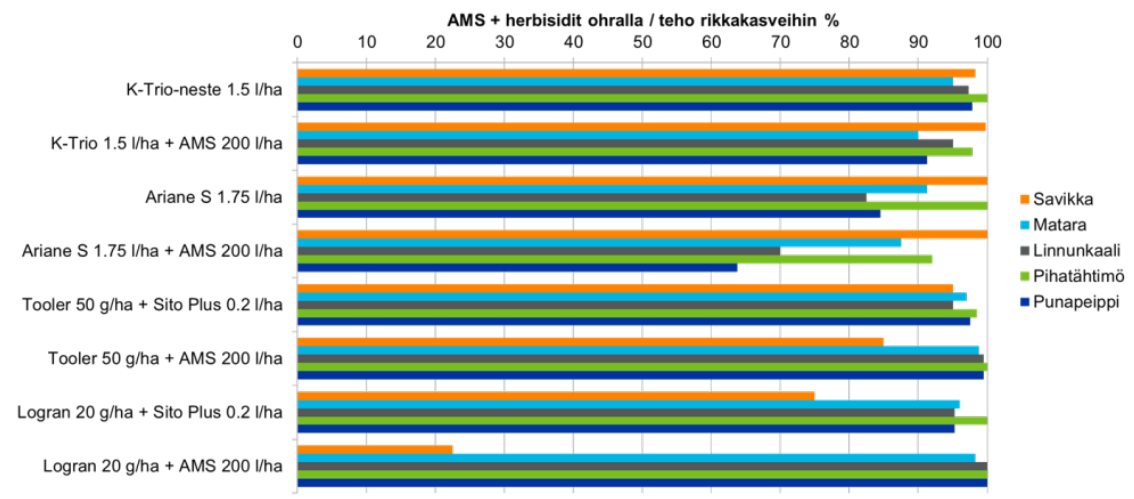

Kuva 2. AMS + herbisidit ohralla, Jokioinen. Käsittelyjen visuaalisesti havainnoitu teho rikkakasveihin 14.7.2017 (30 vrk ruiskutuksesta)

Kesän aikana havainnoitiin myös käsittelyjen aiheuttamat vioitukset viljelykasveissa. K-Trio -neste ja Ariane S aiheuttivat tankkiseoksessa AMS:in kanssa sekä kauralla että ohralla selvää kloroosia ja nekroosia, mutta oireet menivät ohi melko nopeasti. Venla -kaura puitiin 29.9.2017, Vipekka -ohra 7.9.2017, molemmat poikkeuksellisen myöhään viileän ja sateisen kasvukauden vuoksi. Kesällä havaitut lehtivioitukset K-Trio + AMS - ja Ariane S + AMS - käsittelyissä eivät alentaneet kummankaan viljan satoa. Satoerot eivät olleet tilastollisesti merkitseviä. 


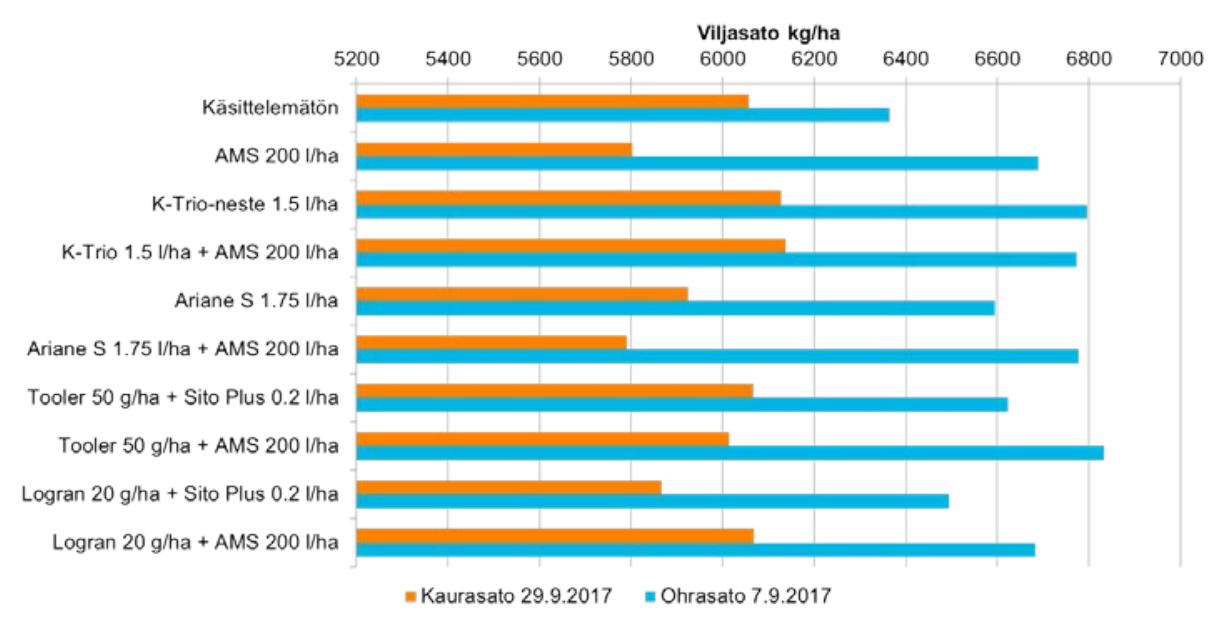

Kuva 3. Kaura- ja ohrasadon määrä kg ha ${ }^{-1}$

\section{Tulosten tarkastelu ja johtopäätökset}

Glyfosaattikokeessa oli valtavasti juolavehnää, minkä vuoksi glyfosaatilla käsittelemättömistä ruuduista ei saatu käytännössä lainkaan vehnäsatoa. Myös pienillä $1 \mathrm{l}$ ha-1) Roundup Bio käyttömäärillä AMS:in kanssa saatiin melko hyvät rikkakasvitehot, mutta AMS:in mahdollinen glyfosaatin tehoa parantava vaikutus jäi osoittamatta, koska koesuunnitelmasta puuttui Roundup Bion pieni annos vesiliuoksessa. Tulevien kasvukausien kenttäkokeisiin tulisi lisätä ko. koejäsen, ja koe voitaisiin toteuttaa pellolla, jonka juolavehnäsaastunta on hieman kohtuullisempi. Herbisidikokeet kauralla ja ohralla olivat koesuunnitelmaltaan ja koepaikoiltaan onnistuneita. Todennäköisesti kiinnitteen puuttuminen AMS -käsittelyissä heikensi Toolerin ja Logranin tehoa varsinkin savikkaan ja emäkkiin. Näidenkin kokeiden toistaminen vähintään yhtenä kasvukautena on kuitenkin tarpeen, ennen kuin pitemmälle meneviä johtopäätöksiä voidaan tehdä. AMS:in lannoitusvaikutus jäi kaikissa kokeissa vähäiseksi, mutta sitä voidaan tarkastella varsinkin tulevien kokeiden jälkeen toisenlaisin tilastollisin menetelmin tehokkaammin.

\section{Kirjallisuusluettelo}

Hallgren, E. \& Nilsson, J. 1989a. Bekämpning av kvickrot (Elymys repens) med Roundup (Glyfosat) och tillsatsmedel. Resultat från ett växthusförsök och ett fätförsök. Sveriges lantbruksuniversitet. 30:e svenska växtsyddskonferensen, Uppsala 1-2 februari 1989, Ogräs och ogräsbekämpning. Vol 1. Rapporter. Uppsala. s. 248-255.

Hallgren, E. \& Nilsson, J. 1989b. Inverkan av Roundup (Glyfosat) med och utan tillstasmedel på ef-fecten mot kvickrot (Elymys repens) vid olika temperature. Ett klimatkammaerförsök. Resultat från ett växthusförsök och ett fätförsök. Sveriges lantbruksuniversitet. 30:e svenska växtsyddskonferensen, Uppsala 1-2 februari 1989, Ogräs och ogräsbekämpning. Vol 1. Rapporter. Uppsala. s. 257-265.

O’Sullivani, P.A., O’Donovani, J.T. \& Hamman, W.M. 1981. Influence of non-ionic surfactants, ammonium sulphate, water quality and spray volume on the phytotoxity of glufosate. Canadian Journal of Plant Science 61: 39-400.

Siimes, K. 2016. Glyfosaatin hajoaminen suomalaisessa peltomaassa. Glyfosaatin ympäristökuormituksen vähentäminen (GlyFos II) -hankkeen aloitusseminaari, Ruissalo, Turku 1. syyskuuta 2016.

https://www.luke.fi/projektit/glyfos-ii.

Suwunnamek, U. \& Parker, C. 1975. Control of Cyperus rotundus with glyphosate: the influence of ammonium sulphate and other additives. Weed Research 15: 13-19.

Turner, D.J. \& Loader, M.P.C. 1980. Effect of ammonium sulphate and other additives upon thephy-totoxicity of glyphosate to Agropyron repens (L.) Beauv. Weed Research 20: 139-146. 